\title{
Porous Electrodes for Low-Temperature Solid Oxide Fuel Cells Fabricated by a Combustion Spray Process
}

\author{
Ying Liu and Meilin Liu* \\ Center for Innovative Fuel Cell and Battery Technologies, School of Materials Science and Engineering, \\ Georgia Institute of Technology, Atlanta, Georgia 30332-0245
}

\begin{abstract}
A new combustion spray process has been developed for depositing films and coatings from particles (or particulate materials) suspended in a flammable liquid. The suspension is pumped to an atomizer to produce a mist of the droplets, which is then ignited to create a combustion flame. The solid particles are thermally activated for formation of films and coatings on a substrate inserted into or near the flame. Solid oxide fuel cells (SOFCs) with porous electrodes fabricated by combustion spray show better performance than those prepared by other fabrication processes (such as conventional dry-pressing and firing) especially at low operating temperatures.
\end{abstract}

\section{Introduction}

$\mathrm{H}$ IGHLY porous films and/or coatings with extremely large surface areas are important to many applications such as catalysis, chemical sensing, and energy storage and conversion. In particular, fabrication of highly efficient porous electrodes for solid oxide fuel cells (SOFCs) represents a great challenge facing the successful realization of low-temperature SOFCs. To date, various fabrication processes have been studied, including physical and chemical deposition processes based on slurry, solution, or vapor phase. $^{1-11}$

The conventional approaches such as tape-casting, ${ }^{1}$ drypressing, ${ }^{2}$ screen-printing, ${ }^{3}$ and spin-coating ${ }^{4}$ have the merits of simplicity, high productivity, and good repeatability. However, the requisite postprocess sintering at high temperatures for a prolonged period of time often leads to limited surface area and poor electrochemical performance. Accordingly, advanced techniques for producing high-quality porous electrodes have been explored, including chemical vapor deposition, ${ }^{5}$ radio frequency (rf) magnetron sputtering, ${ }^{6}$ microwave plasma coating, ${ }^{7}$ laser-assisted deposition, ${ }^{8}$ electrostatic spray deposition (ESD), ${ }^{9}$ and flameassisted vapor deposition (FAVD)..$^{10,11}$

Recently, a relatively new technique, combustion CVD has been adopted to fabricate SOFC components. ${ }^{12-14}$ Porous composite electrodes with nanostructured features and excellent electrochemical performances have been successfully prepared using combustion CVD. Later, the combustion CVD process (that uses only soluble precursors) was further modified by introducing one component of the composite electrodes, $\mathrm{Gd}_{\mathrm{O}_{2}} \mathrm{Ce}_{\mathrm{O}_{8}} \mathrm{O}_{2}$ (GDC), in the form of solid particles. ${ }^{15}$ The other component of the composite electrodes, $\mathrm{Sm}_{0.5} \mathrm{Sr}_{0.5} \mathrm{CoO}_{3}$ (SSC), was introduced as a liquid

J. W. Halloran-contributing editor

Manuscript No. 10949. Received March 29, 2003; approved June 1, 2004. Supported by Department of Energy National Energy Technology Laboratory under Grant No. DE-FG26-01NT41274 and DE-FC26-02NT41572 and by the Georgia Institute of Technology Molecular Design Institute under Prime Contract N00014-95-1-1116 from the Office of Naval Research.

${ }^{*}$ Member, American Ceramic Society. (metal nitrates dissolved in a flammable solvent), formed during deposition, and served as binding agent. The major benefits associated with the suspension rather than solution precursors are low cost and the elimination of a solubility limitation. In this paper, we report a new process, combustion spray, for fabrication of porous films and coatings. In this approach, all components of the electrode material are introduced as solid particles carried by a flammable liquid. SOFC cathodes fabricated by this method showed much lower interfacial polarization resistances at relatively low operating temperatures.

\section{Description of the Process}

Combustion spray is mainly a physical deposition process, which uses solid powders in the size range of nanometer up to millimeter suspended in flammable liquid carrier. The detailed apparatus setup is schematically illustrated in Fig. 1. Solid powders are suspended in an organic liquid carrier by magnetic or ultrasonic stirring or other mechanisms. The resulting mixture is then transported into an atomizer where a fine mist of solution is generated using high-pressure oxidant gas such as air or oxygen. After ignition, a combustion flame is created and sustained by a small pilot ox-hydrogen pilot flame. On burning, collision and sintering of the contained solid particles occur. A coating could be formed if a substrate is present within or near the tip of the flame.

A simple mechanism was used to atomize the suspension. The atomizer consists of two concentric stainless steel tubes. The outer tube has an outer diameter of $3.2 \mathrm{~mm}$ and the inner tube has an outer diameter of $0.79 \mathrm{~mm}$. A mixture of solid powder and flammable liquid carrier is supplied to the inner tube. Atomizing oxidant gas is introduced into the gap between the two tubes. On leaving the concentric tubes, the high-pressure gas mixes with the

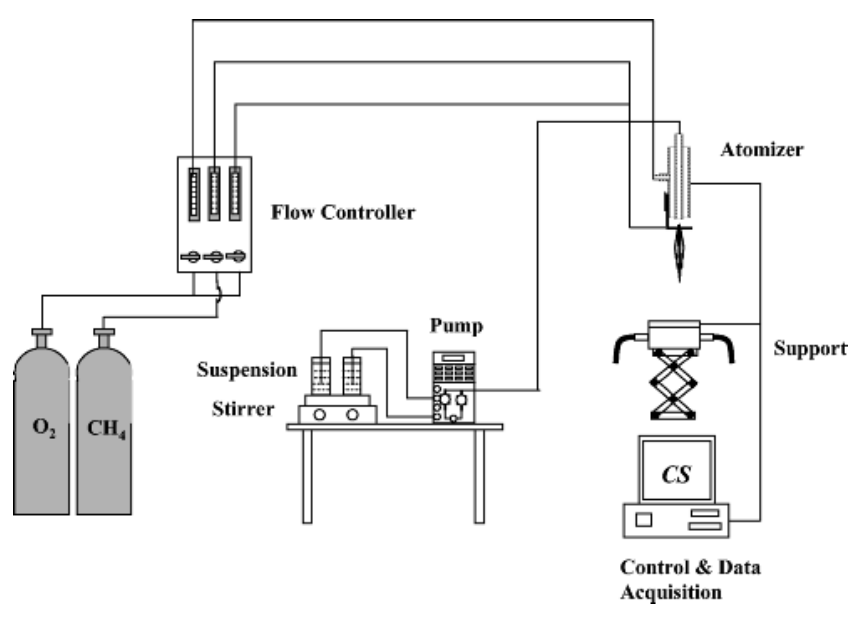

Fig. 1. Schematic apparatus for combustion spray. 
solid-liquid mixture, producing a fine mist. The oxygen/air serves as both oxidant and atomizing gas.

Alternatively, solutions containing desired precursors instead of pure liquid might be used together with solid powders. Two purposes can be achieved: enhancing bonding between particles and particle-substrate when porous films are produced or producing an active coating on the surface of existing solid powders when double-layer particles are desired.

The combustion spray process distinguishes itself from any chemical vapor deposition processes since it is mainly a physical method. Meanwhile, combustion spray is different from all approaches using pure solutions or dry powders as feeding materials ${ }^{16}$ because combustion spray directly uses solid particles carried by a flammable liquid. Further, combustion spray is different from approaches using heating sources other than a combustion flame. In particular, several deposition techniques come close to combustion spray, but they are different in nature. Spray pyrolysis is a thin film forming technique in which a solution is sprayed onto a heated substrate to form a film. The resulting film usually receives additional heat treatment to form the desired phase(s). Another one is thermal spraying, in which dry powders are fed into a gas combustion torch (flame spraying) or plasma torch (plasma spraying), and the melted materials are splattered onto the substrate to form a film. Although a variation of flame spraying uses a solution instead of a powder as feeding materials, ${ }^{17,18}$ so far there is no method found employing a flammable liquid to carry the solid powder. The method most similar to combustion spray is the technique termed combustion CVD, in which the combustion flame is created by the flammable solution rather than an additional torch. ${ }^{19}$ However, it uses solutions containing precursor species, instead of solid powder.

The major advantages of combustion spray over other existing film deposition processes include dramatic reduction in capital investment and operating costs, great flexibility, easy process control, availability of raw materials, little environmental impairment, capability of producing multilayer structures, and flexibility in composition. Combustion spray is conducted in open atmosphere. The thermal environment for bonding of particles and substrate is provided by the combustion flame. No reaction chamber, furnace, or auxiliary heating source is necessary for this process. Solid particles rather than expensive organic reagents common for other deposition processes are used, significantly reducing deposition cost and eliminating the solubility problem. The open-air condition makes it very easy to adjust and control deposition parameters at any stage during deposition. The use of inexpensive, readily available raw materials (usually oxides) also brings environmental advantages compared with other deposition processes where toxic precursors (e.g., chloride or sulfide) must be used. Further, films fabricated using combustion spray do not require postdeposition heat treatment. Comparing with conventional press and firing processes, in which several hours of high-temperature sintering is often required, the combustion spray approach takes only a few minutes to achieve a film thickness up to $20 \mu \mathrm{m}$.

Combustion spray can be used for deposition of films and coatings with a wide variety of compositions, structures, and morphologies, from thin films to thick coatings, from dense films to porous films, and also for surface coated particles. Some of the potential applications include (a) porous films for energy storage and conversion, such as electrodes for solid oxide fuel cells, batteries, and sensors; (b) catalysts for chemical reactions; (c) dense oxide coating for hightemperature applications; (d) semiconductors and buffer layers; and (e) electro-opotic materials and devices.

\section{Experimental Procedure}

Anode (65 wt\% NiO-35 wt\% GDC) supported GDC substrates were prepared by co-pressing followed by sintering as described elsewhere. ${ }^{20}$ Cathodes were deposited onto the substrates using a combustion spray process. Powders of SSC and GDC (Rhodia E \& $\mathrm{C}$, Cranbury, NJ) have an average particle size of 0.9 and $0.3 \mu \mathrm{m}$, respectively. The solid particles of SSC and GDC were put in ethanol in a weight ratio of 7:3. Before deposition, the solid-liquid mixture was ultrasonically dispersed to break down particle agglomeration. During deposition, a magnetic stir bare was used to prevent particles from settling down. Deposition was conducted at $1250^{\circ} \mathrm{C}$ for $10 \mathrm{~min}$. Deposition temperature was measured by placing type $\mathrm{K}$ thermocouples near substrate surfaces.

The microscopic features of the prepared electrodes were characterized using a scanning electron microscope (Hitachi S-800) equipped with an energy dispersive spectroscopy (EDS) attachment. Electrochemical performances of the symmetrical cells were measured in ambient air from $450^{\circ}$ to $650^{\circ} \mathrm{C}$. Impedance spectra were typically acquired in the frequency range from $0.01 \mathrm{~Hz}$ to $100 \mathrm{kHz}$ with an EG\&G potentiostat/galvanostat (Model 273A) and a lock-in amplifier (Model 5210).

\section{Results and Discussion}

Shown in Fig. 2(a) is a cross-sectional view of an SOFC with a composite cathode consisting of SSC and GDC fabricated by combustion spray. The bottom layers are a $30 \mu \mathrm{m}$ dense GDC
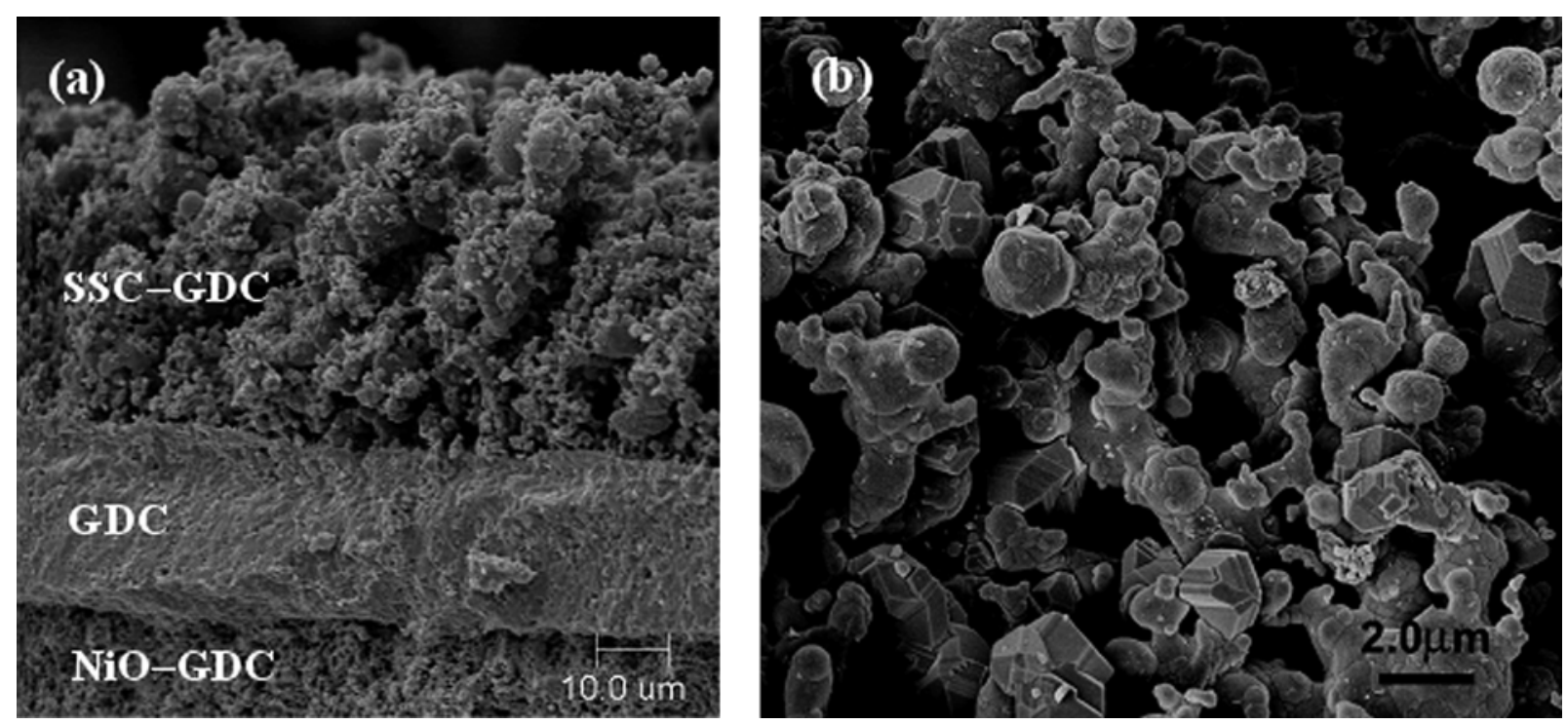

Fig. 2. (a) Cross-sectional view of a solid oxide fuel cell with SSC-GDC cathode fabricated by a combustion-spray process and (b) higher magnification SEM micrographs of the cathode. 
electrolyte supported by a porous anode consisting of $65 \mathrm{wt} \% \mathrm{NiO}$ and $35 \mathrm{wt} \%$ GDC and the top layer is a $40 \mu \mathrm{m}$ thick cathode prepared using combustion spray. A higher magnification SEM micrograph of the cathode, Fig. 2(b), shows that the sizes of most grains are in the range of $0.5-2.0 \mu \mathrm{m}$, and the grains are well-attached to each other. The necking or bridging between grains is evident. Meanwhile, very large voids are present between grains. This microscopic characteristic is different from samples prepared by conventional dry-pressing and firing processes, in which interconnected gas channels are limited. Another obvious feature is that most grains have a spherical shape; however, some grains are faceted, suggesting limited vapor-phase mass transport has occurred during deposition.

Shown in Fig. 3 are some typical impedance spectra of the fuel cells as measured at $450^{\circ}-650^{\circ} \mathrm{C}$. It appears that each spectrum consists of at least two overlapped loops, implying that more than two processes have contributed to the impedance responses. While it is not clear how to correlate the details of the impedance features with interfacial processes, it is straightforward to determine the total interfacial polarization resistances of the cell, $R_{\mathrm{p}}$. Since GDC has some electronic conduction under fuel cell conditions, the interfacial polarization resistances cannot be directly read from the impedance data. Open cell voltages and Nernst potential have been combined with the impedance data to calculate the interfacial polarization resistances. ${ }^{21}$ After the correction due to electronic conduction of GDC, the interfacial polarization resistances of the cell at $500^{\circ}$ and $600^{\circ} \mathrm{C}$ were 1.045 and $0.195 \Omega \cdot \mathrm{cm}^{2}$, respectively, as shown in Fig. 3(a). Shown in Fig. 3(b) are the interfacial polarization resistances compared with data for cells of identical composition with electrodes fabricated using screen-printing. The interfacial polarization resistances for the cell with cathodes fabricated by combustion spray are comparable to those with screen-printed electrodes at $550^{\circ}-600^{\circ} \mathrm{C}$, but a little smaller at temperatures below $550^{\circ} \mathrm{C}$. In addition, the activation energy for combustion-sprayed cathodes appears to be lower than that of screen-printed cathodes. It is noted that the interfacial polarization
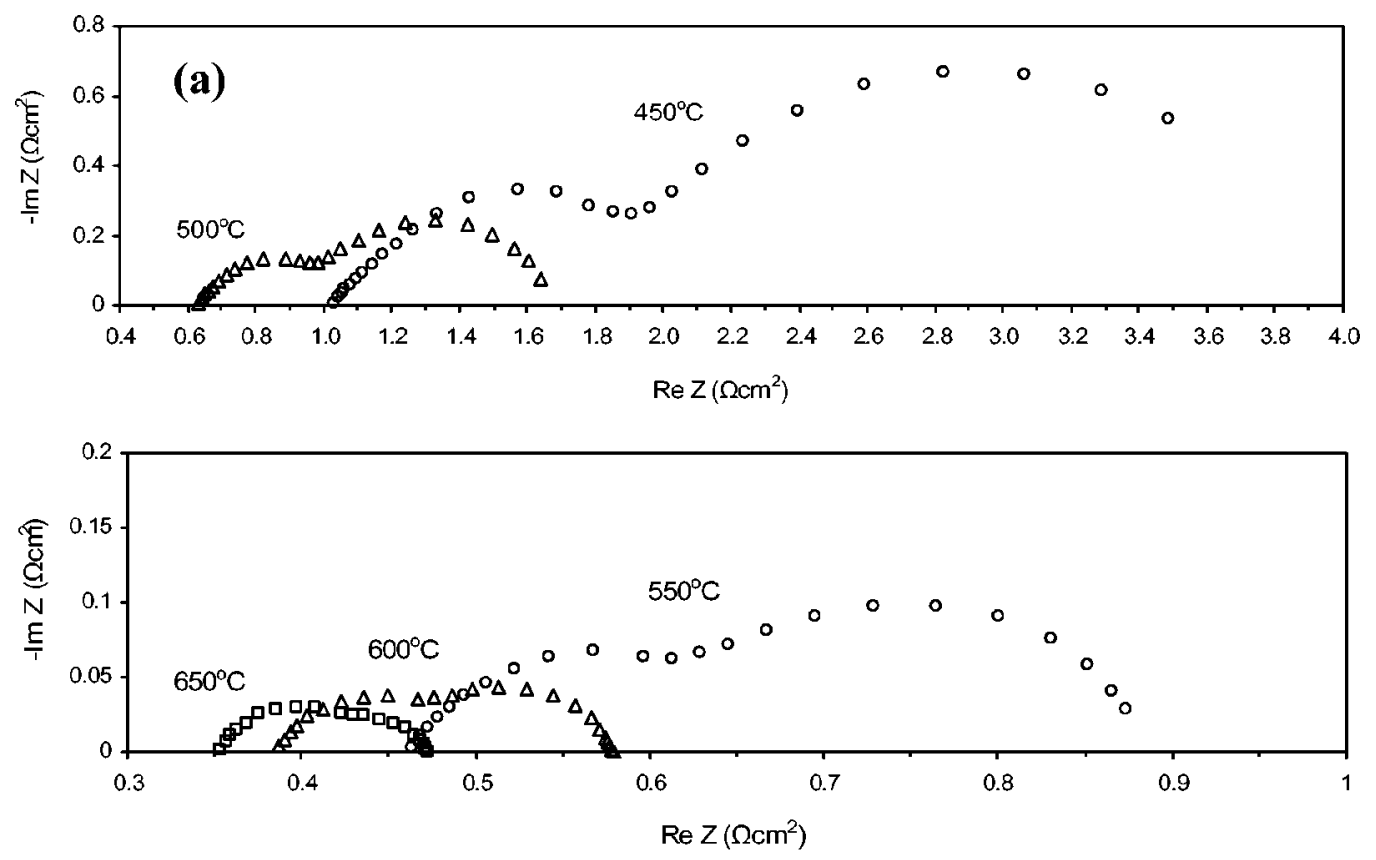

Temperature ${ }^{\circ} \mathrm{C}$

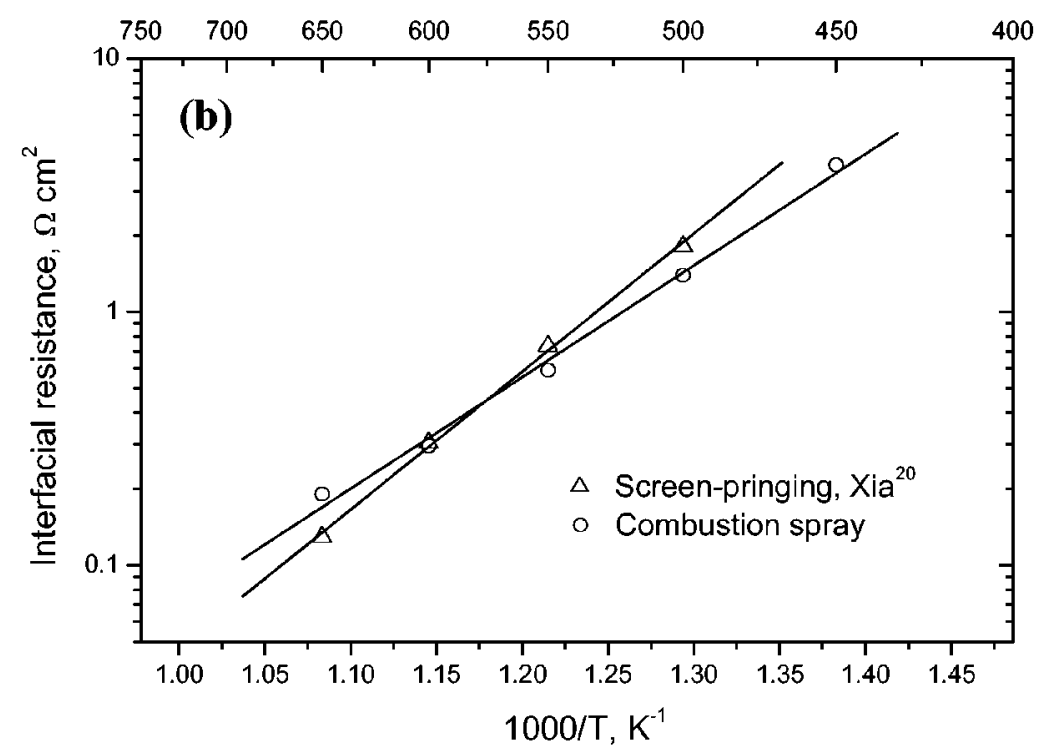

Fig. 3. (a) Impedance spectra of a single fuel cell as measured using a two-electrode configuration and (b) comparison of interfacial polarization resistances as determined from impedance spectra for electrodes fabricated using different techniques: screen-printing ${ }^{20}$ and combustion spray. 


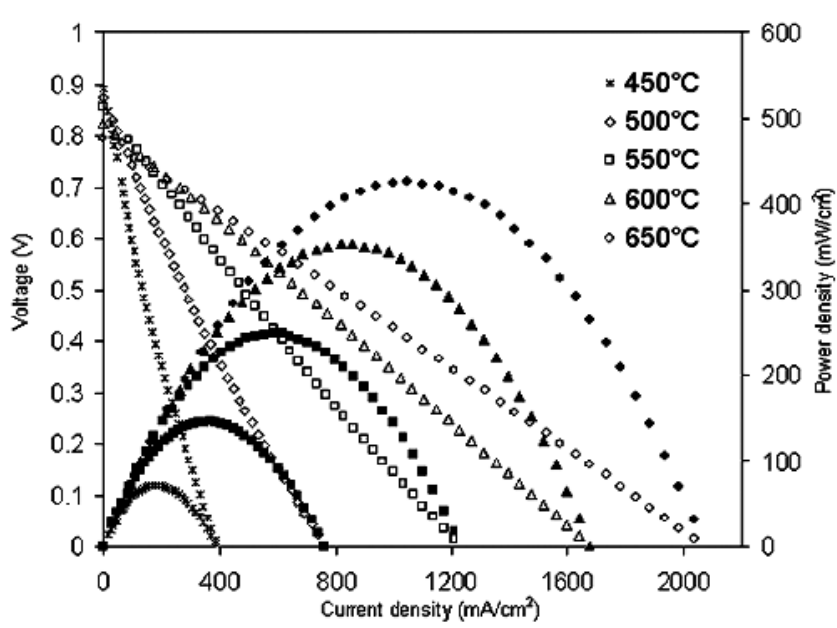

Fig. 4. Cell voltages and power densities as a function of current density for fuel cells with SSC-GDC cathode fabricated by a combustion-spray process.

resistances $\left(R_{\mathrm{p}}\right)$ include both the anode-electrolyte polarization resistance $\left(R_{\mathrm{p}, \mathrm{a}}\right)$ and the cathode-electrolyte polarization resistance $\left(R_{\mathrm{p}, \mathrm{c}}\right)$. However, $R_{\mathrm{p}, \mathrm{a}}$ remain the same for all cells and are relative small. $^{20}$

Shown in Fig. 4 is the performance of the fuel cell operated at different temperatures. The peak power densities at $500^{\circ}, 550^{\circ}$, $600^{\circ}$, and $650^{\circ} \mathrm{C}$ were $145,248,352$, and $425 \mathrm{~mW} / \mathrm{cm}^{2}$, respectively. The electrochemical performance of the fuel cell with cathode prepared by combustion spray is equal to or better than those fabricated using conventional firing processes, which usually require $3-5 \mathrm{~h}$ of high-temperature sintering.

\section{Conclusions}

A combustion-spray process has been developed for fabrication of porous electrodes for solid oxide fuel cells. Solid ceramic particles, suspended in a flammable liquid carrier, are feed to an atomizer where a fine mist of solution is generated and combusted. The high-velocity flame provides the energy needed for collision and sintering of the contained solid particles to produce porous electrodes. The demonstrated fast deposition rates (i.e., $40 \mu \mathrm{m}$ in $10 \mathrm{~min}$ ) and the elimination of postdeposition firing make this process practically valuable. This technique has been successfully used for fabrication of porous SSC-GDC cathodes for SOFCs. The performance of the porous SOFC electrodes fabricated by combustion spray is equal to or better than those prepared by the conventional techniques, especially at low operating temperatures.

\section{References}

${ }^{1}$ O. Costa-Nunes, J. M. Vohs, and R. J. Gorte, "A Study of Direct-Conversion SOFC with $n$-Butane at Higher Fuel Utilization," J. Electrochem. Soc., 150 [7] A858-A863 (2003).

${ }^{2} \mathrm{~S}$. Zha, W. Rauch, and M. Liu, "Ni-Ce ${ }_{0.9} \mathrm{Gd}_{0.1} \mathrm{O}_{1.95}$ Anode for GDC ElectrolyteBased Low-Temperature SOFCs," Solid State Ionics, 166 [3-4] 241-50 (2004).

${ }^{3} \mathrm{C}$. Xia and M. Liu, "Low-Temperature SOFCs Based on $\mathrm{Gd}_{0.1} \mathrm{Ce}_{0.9} \mathrm{O}_{1.95}$ Fabricated by Dry Pressing," Solid State Ionics, 144 [3-4] 249-55 (2001).

${ }^{4}$ E. P. Murray and S. A. Barnett, "( $\left.\mathrm{La}, \mathrm{Sr}\right) \mathrm{MnO}_{3}-(\mathrm{Ce}, \mathrm{Gd}) \mathrm{O}_{2-x}$ Composite Cathodes for Solid Oxide Fuel Cells," Solid State Ionics, 143 [3-4] 265-73 (2001).

${ }^{5}$ G. L. Bertrand, G. Caboche, and L.-C. Dufour, "Low-Pressure-MOCVD $\mathrm{LaMnO}_{3 \pm \delta}$ Very Thin Films on YSZ (100) Optimized for Studies of the Triple Phase Boundary," Solid State Ionics, 129 [1-4] 219-35 (2000).

${ }^{6} \mathrm{~K}$. Hayashi, O. Yamamoto, Y. Nishigaki, and H. Minoura, "Sputtered $\mathrm{La}_{0.5} \mathrm{Sr}_{0.5} \mathrm{MnO}_{3}-$ Yttria Stabilized Zirconia Composite Film Electrodes for SOFC," Solid State Ionics, 98 [1-2] 49-55 (1997).

${ }^{7}$ H. B. Wang, J. F. Gao, D. K. Peng, and G. Y. Meng, "Plasma Deposition of $\mathrm{La}_{0.8} \mathrm{Sr}_{0.2} \mathrm{MnO}_{3}$ Thin Films on Yttria-Stabilized Zirconia from Aerosol Precursor," Mater. Chem. Phys., 72 [3] 297-300 (2001).

${ }^{8}$ L. G. Coccia, G. C. Tyrrell, J. A. Kilner, D. Waller, R. J. Chater, and I. W. Boyd, "Pulsed Laser Deposition of Novel Materials for Thin Film Solid Oxide Fuel Cell Applications: $\mathrm{Ce}_{0.9} \mathrm{Gd}_{0.1} \mathrm{O}_{1.95}, \mathrm{La}_{0.7} \mathrm{Sr}_{0.3} \mathrm{CoO}_{y}$ and $\mathrm{La}_{0.7} \mathrm{Sr}_{0.3} \mathrm{Co}_{0.2} \mathrm{Fe}_{0.8} \mathrm{O}_{y},{ }^{\prime}$ Appl. Surf. Sci., 96 [8] 795-801 (1996).

${ }^{9}$ I. Taniguchi, R.C. Landschoot, and J. Schoonman, "Fabrication of La1- $x \operatorname{Sr} x$ Co1yFeyO3 Thin Films by Electrostatic Spray Deposition," Solid State Ionics, 156 [1-2] 1-13 (2003).

${ }^{10}$ K. L. Choy, S. Charojrochkul, and B. C. H. Steele, "Fabrication of Cathode for Solid Oxide Fuel Cells Using Flame Assisted Vapour Deposition Technique," Solid State Ionics, 96 [1-2] 49-54 (1997).

${ }^{11}$ S. Charojrochkul, K. L. Choy, and B. C. H. Steele, "Cathode/Electrolyte Systems for Solid Oxide Fuel Cells Fabricated Using Flame Assisted Vapour Deposition," Solid State Ionics, 121 [1-4] 107-13 (1999).

${ }^{12}$ Y. Liu, W. Rauch, and M. Liu, "Nano-Particles and Nanostructured Electrodes Fabricated by Combustion CVD"; pp. 205-15 in Solid State Ionic Devices III. Edited by E. Wachsman, K. Swider-lyons, M. F. Carolan, F. H. Garzon, M. Liu, and J. R. Stetter. The Electrochemical Society, Pennington, NJ, 2002.

${ }^{13}$ Y. Liu, W. Rauch, S. Zha, and M. Liu, "Fabrication of $\mathrm{Sm}_{0.5} \mathrm{Sr}_{0.5} \mathrm{CoO}_{3-\delta^{-}}$ $\mathrm{Sm}_{0.1} \mathrm{Ce}_{0.9} \mathrm{O}_{2-\delta}$ Cathodes for Solid Oxide Fuel Cells Using Combustion CVD," Solid State Ionics, 166 [3-4] 261-68 (2004).

${ }^{14}$ Y. Liu, S. Zha, and M. Liu, "Novel Nanostructured Electrodes for Solid Oxide Fuel Cells Fabricated by Combustion Chemical Vapor Deposition (CVD)," Adv. Mater., 16 [3] 256-60 (2004)

${ }^{15}$ Y. Liu, S. Zha, and M. Liu, "Nanocomposite Electrodes Fabricated by a Particle-Solution Spraying Process for Low-Temperature SOFCs," Chem. Mater., 16 [18] 3502-506 (2004).

${ }^{16}$ W. J. Lackey, W. B. Carter, J. A. Hanigofsky, D. N. Hill, E. K. Barefield, G. Neumeier, D. F. O'Brien, M. J. Shapiro, J. R. Thompson, A. J. Green, T. S. Moss III, R. A. Jake, and K. R. Efferson, "Rapid Chemical Vapor Deposition of Superconducting $\mathrm{YBa}_{2} \mathrm{Cu}_{3} \mathrm{O}_{x}, "$ Appl. Phys. Lett., 56 [12] 1175-77 (1990).

${ }^{17}$ M. R. Zachariah and S. Huzarewicz, "Aerosol Processing of YBaCuO Superconductors in a Flame Reactor," J. Mater. Res., 6 [2] 264-69 (1991).

${ }^{18}$ B. D. Merkle, R. N. Kniseley, F. A. Schmidt, and I. E. Anderson, "Superconducting $\mathrm{YBa}_{2} \mathrm{Cu}_{3} \mathrm{O}_{x}$ Particulate Produced by Total Consumption Burner Processing," Mater. Sci. Eng. A-Struct., 124 [1] 31-38 (1990).

${ }^{19}$ A. T. Hunt, W. B. Carter, and J. K. Cochran, "Combustion Chemical Vapor Deposition: A Novel Thin-Film Deposition Technique," Appl. Phys. Lett., 63 [2] 266-68 (1993).

${ }^{20}$ C. Xia, W. Rauch, F. Chen, and M. Liu, " $\mathrm{Sm}_{0.5} \mathrm{Sr}_{0.5} \mathrm{CoO}_{3}$ Cathodes for Low-Temperature SOFCs," Solid State Ionics, 149 [1-2] 11-19 (2002).

${ }^{21}$ M. Liu and H. Wu, "Effect of Interfacial Resistance on Determination of Transport Properties of Mixed-Conducting Electrolytes," J. Electrochem. Soc., 143 [6] L109-L112 (1996). 